\title{
PEMBERDAYAAN IBU DALAM MENGENALI DIARE PADA ANAK DAN CARA PENCEGAHAN DIARE DI POSYANDU KALI KEJAMBON KECAMATAN TEMBELANG KABUPATEN JOMBANG
}

\author{
Mamik Ratnawati ${ }^{1^{*}}$, Monika Sawitri Prihatini ${ }^{2}$, Rini Hayu Lestari ${ }^{3}$ \\ STIKES Pemkab Jombang \\ 1'mamik.perawat@gmail.com, ${ }^{2}$ monika.sawitri@yahoo.co.id, ${ }^{3}$ hanifsaify1998@gmail.com
}

\begin{abstract}
ABSTRAK
Abstrak: Penyakit diare masih menjadi masalah global dengan derajat kesakitan dan kematian yang tinggi di berbagai negara terutama di negara berkembang, dan juga sebagai salah satu penyebab utama tingginya angka kesakitan dan kematian anak di dunia. Tujuan dari kegiatan ini adalah untuk memberikan edukasi kepada ibu balita agar mengerti dan paham tentang diare dan pencegahannya di posyandu Desa Kali Kejambon Kecamatan Tembelang kabupaten Jombang. Kegiatan pengabdian masyarakat dengan Pemberdayaan Ibu Dalam Mengenali Diare Pada Anak Dan Cara Pencegahan Diare di Posyandu Kali Kejambon Kecamatan Tembelang Kabupaten Jombang berjalan dengan baik, sebanyak 50 orang ibu balita yang hadir dalam kegiatan ini dan terdapat $80 \%$ ibu balita paham dengan materi yang disampaikan oleh tim pelaksana pengabdian masyarakat serta terdapat umpan balik dengan memberikan pertanyaan kepada pelaksana kegiatan untuk pembahasan yang belum dimengerti. Bagi para ibu balita agar selalu waspada dengan kejadian diare pada balita karena diare merupakan bukan kasus yang bisa diremehkan dan bagi tenaga kesehatan agar selalu memberikan edukasi tentang penyakit-penyakit yang sering terjadi pada anak-anak agar tidak terjadi bahaya dan komplikasi.

Kata Kunci: Diare, Cara Pencegahan

Abstract: Diarrhea is still a global problem with high degrees of illness and death in various countries, especially in developing countries, and also as one of the main causes of high child morbidity and mortality in the world. The purpose of this activity is to provide education to mothers of children under five to understand and understand diarrhea and its prevention at the Posyandu in Kali Kejambon Village, Tembelang District, Jombang Regency. Community service activities with the Empowerment of Mothers in Recognizing Diarrhea in Children and How to Prevent Diarrhea in the Kali Kejambon Posyandu in Tembelang District, Jombang Regency went well, as many as 50 under-five mothers attended this activity and $80 \%$ of toddlers understood the material delivered by the team implementing community service and providing feedback by giving questions to the implementers of activities for discussions that have not been understood. For mothers of toddlers to always be aware of the incidence of diarrhea in toddlers because diarrhea is not a case that can be underestimated and for health workers to always provide education about diseases that often occur in children so that there is no danger and complications.

Keywords: Diarrhea, Prevention
\end{abstract}

\section{A. LATAR BELAKANG}

Penyakit diare masih menjadi masalah global dengan derajat kesakitan dan kematian yang tinggi di berbagai negara terutama di negara berkembang, dan juga sebagai salah 
satu penyebab utama tingginya angka kesakitan dan kematian anak di dunia.

Secara umum, diperkirakan lebih dari 10 juta anak berusia kurang dari 5 tahun meninggal setiap tahunnya di dunia dimana sekitar 20\% meninggal karena infeksi diare (Magdarina, 2010 dalam Hardi dkk, 2012).Menurut data World Health Organization (WHO) pada tahun 2013, setiap tahunnya ada sekitar 1,7 miliar kasus diare dengan angka kematian 760.000 anak dibawah 5 tahun (Siregar dkk, 2016).

Berdasarkan hasil Riskesdas prevalensi diare pada balita di Indonesia mengalami peningkatan setiap tahunnya. Riskesdas (2007) melaporkan bahwa angka nasional prevalensi diare adalah 9,0\%. Prevalensi diare berdasarkan kelompok umur pada balita (1-4 tahun) terlihat tinggi menurut hasil Riskesdas (2007), yaitu 16,7\%. Demikian pula pada bayi ( $<1$ tahun), yaitu 16,5\% (Kemenkes RI, 2011 dalam Siregar dkk, 2016).

Provinsi Jawa Timur merupakan provinsi yang memberikan kontribusi besar terhadap jumlah kasus diare pada balita di Indonesia. Hal ini dikarenakan Jawa Timur merupakan provinsi dengan jumlah penduduk terbanyak kedua di Indonesia dengan presentase diare pada balita cukup tinggi sebesar 6,6\% (Profil Kesehatan Indonesia, 2013 dalam Ayuningrum dan Salamah, 2015). Berdasarkan data dari Dinas Kesehatan Kabupaten Jombang tahun 2016 jumlah penderita diare yang ditemukan dan ditangani di Kabupaten Jombang adalah 25.978. Sedangkan jumlah penderita diare terbanyak berada di wilayah kerja Puskesmas Bareng dengan jumlah penderita sebanyak 2.231. Berdasarkan data dari Puskesmas Bareng tahun 2016 didapatkan bahwa jumlah penderita diare pada balita sebanyak 669 balita.

Dari hasil penemuan didapatkan bahwa diare terbesar pada balita terletak di Desa Bareng dengan jumlah penderita sebanyak 390 balita. Rendahnya cakupan personal hygiene dan sanitasi lingkungan sering sekali menjadi faktor resiko terjadinya KLB diare (Kemenkes RI, 2011 dalam Mokodompit dkk, 2015). Faktor personal hygiene (kebersihan perorangan) ibu juga sangat berpengaruh terhadap kejadian diare pada balita. Perilaku ibu yang tidak hygienis seperti tidak mencuci tangan pada saat memberi makan anak, tidak mencuci bersihperalatan masak dan makan, dapat menyebabkan balita terkena diare. Personal hygiene ibu dan sanitasi lingkungan perumahan yang baik bisa terwujud apabila didukung oleh perilaku masyarakat yang baik (Depkes RI, 2008 dalam Siregar 2016). Salah satu upaya yang bisa dilakukan untuk mencegah menyebar dan menularnya diare ialah dengan menjaga kebersihan perorangan karena faktor kebersihan menjadi faktor yang penting untuk menghindarkan anak dari penyakit diare.

\section{B. DIARE}

Diare adalah keadaan frekuensi buang air besar lebih dari 4 kali pada bayi dan lebih dari 3 kali pada anak, konsistensi feses encer, dapat 
berwarna hijau atau dapat pula bercampur lendir dan darah/lendir saja (Ngastiyah, 2005).

Manifestasi klinis yang terjadi pada klien diare berdasarkan dehidrasi: 1) Diare Tanpa Dehidrasi, ciri-cirinya jika pada balita, ia tetap aktif, memiliki keinginan untuk minum seperti biasa, mata tidak cekung, dan turgor kembali segera. Namun, Balita akan kehilangan cairan $<5 \%$ dari berat badan, 2) Diare Dehidrasi Ringan/Sedang, biasanya Balita mengalami gelisah atau rewel, mata cekung, rasa haus meningkat, turgor kembali lambat, dan kehilangan cairan 5-10\% dari berat badan, 3) Diare Dehidrasi Berat, ditandai dengan lesu/lunglai, mata cekung, malas minum, turgor kembali sangat lambat $>2$ detik, dan kehilangan cairan $>10 \%$ dari berat badan.

Untuk mengatasi penyakit diare, berikut tindakan pencegahan dehidrasi yang bisa dilakukan di tingkat rumah tangga jika balita mengalami diare: 1) Memberikan ASI lebih sering dan lebih lama dari biasanya, 2) Pemberian oralit untuk mencegah dehidrasi sampai diare berhenti, 3) Memberikan obat Zinc yang tersedia di apotek, Puskesmas, dan rumah sakit. Diberikan sekali sehari selama 10 hari berturut-turut meskipun diare sudah berhenti. Zinc dapat mengurangi parahnya diare, mengurangi dursi dan mencegah berulangnya diare 2 sampai 3 bulan ke depan, 4) Memberikan cairan rumah tangga, seperti sayur, kuah sup, dan air mineral, 5) Segera membawa Balita diare ke sarana kesehatan, 6) Pemberian makanan sesuai umur : a) Bayi berusia 0-6 bulan : hanya diberikan ASI sesuai keinginan anak, paling sedikit 8 kali sehari (pagi, siang, maupun malam hari). Jangan berikan makanan atau minuman lain selain ASI, b) Bayi berusia 6-24 bulan: Teruskan pemberian ASI, mulai memberikan Makanan Pendamping ASI (MP ASI) yang teksturnya lembut seperti bubur, susu, dan pisang, c) Balita umur 9 sampai 12 bulan: Teruskan pemberian ASI, berikan MP ASI lebih padat dan kasar seperti nasi tim, bubur nasi, tambahkan telur/ayam/ikan/tempe/wortel/kacang hijau, d) Balita umur 12 sampai 24 bulan: teruskan pemberian ASI, berikan makanan keluarga secara bertahap sesuai dengan kemampuan anak, e) Balita umur 2 tahun lebih: berikan makanan keluarga 3x sehari, sebanyak 1/3-1/2 porsi makan orang dewasa. Berikan pula makanan selingan kaya gizi 2x sehari di antara waktu makan.

Anjuran Makan untuk Diare Persisten: 1) Jika anak masih mendapat ASI: berikan lebih sering dan lebih lama, pagi, siang, dan malam, 2) Jika anak mendapat susu selain ASI: kurangi pemberian susu tersebut dan tingkatkan pemberian ASI. Gantikan setengah bagian susu dengan bubur nasi ditambah tempe, jangan beri susu kental manis. Untuk makanan lain, ikuti anjuran pemberian makan sesuai dengan kelompok umur.

\section{METODE PELAKSANAAN}

Kegiatan ini dilaksanakan di Posyandu Kali Kejambon Kecamatan Tembelang Kabupaten dengan jumlah ibu balita 50 orang. Adapun kegiatan pengabdian masyarakat dengan tahapan sebagai berikut:

1. Sosialisasi atau penyuluhan tentang diare dan mencegahannya:

a. Pelaksana dibantu anggota LPPM sebanyak 3 orang anggota dan 5 orang mahasiswa dalam melaksanakan pengabdian masyarakat. 
b. Pelaksanaan dilakukan di posyandu mulai pukul 08.00 WIB sampai dengan selesai

c. Ibu balita yang hadir saat pelaksanaan pengabdian masyarakat mengisi daftar hadir pelaksanaan sebanyak 50 orang

d. Ibu balita berkumpul di posyandu untuk menerima pengarahan dan prosedur kegiatan yang akan dilaksanakan

e. Tahap pertama tim abdimas memberikan penyuluhan tentang diare dan pencegahannya

2. Diskusi atau tanya jawab terkait materi yang telah disampaikan

Setelah selesai penyuluhan selesai diadakan tanya jawab perihal topik yang sudah diberikan

3. Simulasi cara pembuatan oralit di rumah

Tahap kedua pelaksana memberikan simulasi cara pembuatan oralit di rumah

\section{HASIL DAN PEMBAHASAN}

Kegiatan pengabdian masyarakat dengan Pemberdayaan Ibu Dalam Mengenali Diare Pada Anak Dan Cara Pencegahan Diare di Posyandu Kali Kejambon Kecamatan Tembelang Kabupaten Jombang" berjalan dengan baik, ibu balita senang dengan kegiatan tersebut dan memahami edukasi yang diberikan. Tetapi sebagian ada yang belum paham dengan cara pembuatan oralit di rumah sehingga pelaksana kegiatan mengulang kembali demonstrasi cara pembuatan oralit di rumah. Ibu balita juga sebagian ada yang tidak paham sebanyak 20\% ibu balita tentang bahaya dan komplikasi dengan diare pada balita. Peserta ibu balita yang hadir saat kegiatan pengabdian masyarakat sejumlah 50 ibu balita. Kegiatan ini bisa tercapai sesuai dengan kriteria yang diharapkan.

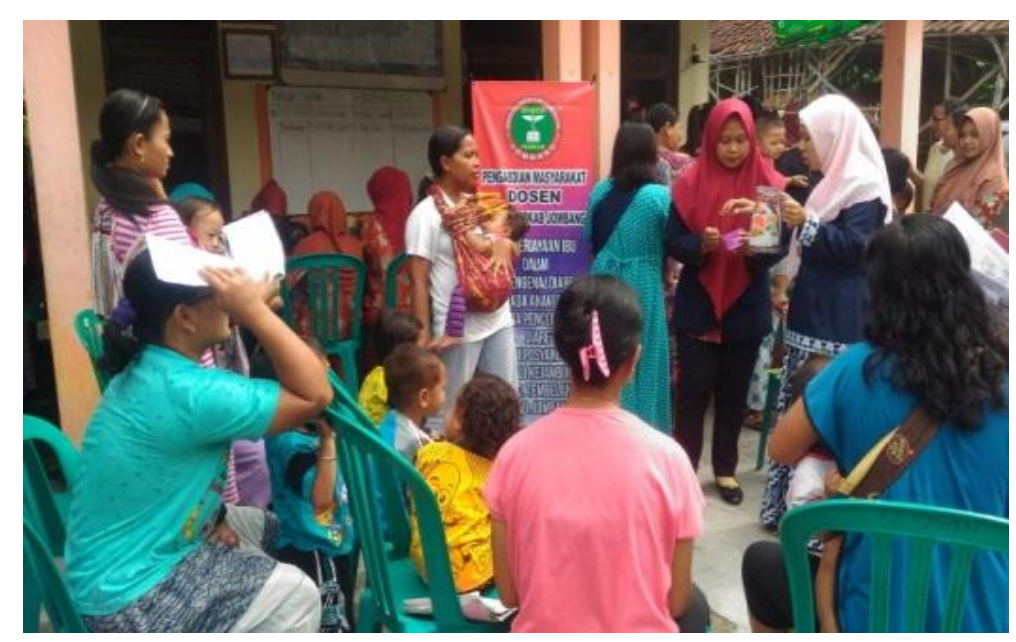

Gambar 1. Demonstrasi Cara Pembuatan Oralit di Rumah

Manfaat dari kegiatan pengabdian masyarakat bisa dirasakan oleh ibu balita yaitu bisa mengerti dan memahami tentang diare serta pencegahanya dan bahaya serta komplikasi yang ditimbulkan. Dari demonstrasi pembuatan oralit di rumah ibu balita banyak yang bisa melakukan pembuatan oralit. 


\section{E. SIMPULAN DAN SARAN}

Dengan adanya pengabdian masyarakat ini diharapkan menambah pengetahuan ibu balita perihal pencegahan diare di rumah secara dini, pembuatan oralit sendiri di rumah agar bisa mengatasi kehilangan cairan secara cepat sehingga tidak sampai terjadi dehidrasi. Bagi ibu dan balita secara rutin datang ke posyandu karena setiap pertemuan kegiatan di posyandu selalu ada penyuluhan datau kegiatan yang lain yang bermanfaat bagi ibu dan balita serta bagi tenaga kesehatan agar selalu memberikan edukasi bagi ibu dan balita di setiap pertemuan kegiatan posyandu balita.

\section{UCAPAN TERIMA KASIH}

Tim Abdimas mengucapkan terima kasih kepada Unit Penelitian dan Pengabdian Masyarakat (UPPM) Sekolah Tinggi Ilmu Kesehatan Pemkab Jombang yang telah mendukung kegiatan pengabdian ini sehingga terlaksana dengan baik. Selanjutnya, tim Abdimas mengucapkan terima kasih kepada ibu balita yang hadir pada kegiatan posyandu di Desa Kali Kejambon Kecamatan Tembelang Kabupaten Jombang beserta kader posyandu dan bidan desa yang telah bersedia mengikuti kegiatan ini dengan semangat.

Semoga kegiatan ini menjadi inspirasi buat kita semua agar lebih memahami dan dapat mengaplikasikan pencegahan diare pada balita sehingga tidak banyak terjadi komplikasi serta kematian pada balita yang diakibatkan diare.

\section{DAFTAR RUJUKAN}

[1] Ayuningrum, Feby Victiani dan Mutiah Salamah. (2015). Analisis faktor sanitasi dan sumber air minum yang mempengaruhi insiden diare pada balita di Jawa Timur dengan regresi logistik biner. Online http://ejurnal.its.ac.id

[2] Medika Ferlando, Herry Tomy dan Supriyono Asfawi. (2014). Hubungan antara sanitasi lingkungan dan personal hygiene ibu dengan kejadian diare pada balita di wilayah kerja Puskesmas Mangkang tahun 2014. Online: http://eprints.dinus.ac.id

[3] Hardi, Amir Rahman dkk. (2012). Faktor - faktor yang mempengaruhi diare pada balita di wilayah kerja puskesams Baranglompo kecamatan Ujung Tanah 2012. Online http://repository.unhas.ac.id.

[4] Hanifah, Maryam. (2010). Hubungan usia dan tingkat pendidikan dengan pengetahuan wanita usia 20-50 tahun tentang periksa payudara sendiri tahun 2010. Online http://repository.uinjkt.ac.id.

[5] Isro'in, Laily dan Andarmoyo, Sulistyo. (2012). Personal Hygiene. Yogyakarta: Graha IlmuLestari.

[6] Mokodompit, Amanda dkk. (2015). Hubungan tindakan personal hygiene ibu dengan kejadian diare pada balita di Puskesmas Bilalang kota Kotamobagu. Online http://ejournal.unsrat.ac.id 